\title{
BMJ Open Effect of work schedule on prospective antidepressant prescriptions in Sweden: a 2-year sex-stratified analysis using national drug registry data
}

Amy L Hall, ${ }^{1,2}$ Göran Kecklund, ${ }^{2}$ Constanze Leineweber, ${ }^{2}{\text { Philip } \text { Tucker }^{2,3}}^{2}$

To cite: Hall AL, Kecklund G, Leineweber $\mathrm{C}$, et al. Effect of work schedule on prospective antidepressant prescriptions in Sweden: a 2-year sex-stratified analysis using national drug registry data. BMJ Open 2019;9:e023247. doi:10.1136/ bmjopen-2018-023247

- Prepublication history for this paper is available online. To view these files please visit the journal online (http://dx.doi org/10.1136/bmjopen-2018023247).

Received 28 March 2018 Revised 22 November 2018 Accepted 28 November 2018

A) Check for updates

(C) Author(s) (or their employer(s)) 2019. Re-use permitted under CC BY-NC. No commercial re-use. See rights and permissions. Published by BMJ.

${ }^{1}$ International Agency for Research on Cancer, Lyon, France

${ }^{2}$ Stress Research Institute, Stockholm University,

Stockholm, Sweden

${ }^{3}$ Department of Psychology,

Swansea University, Wales, UK

Correspondence to

Dr Amy L Hall;

halla@fellows.iarc.fr

\section{ABSTRACT}

Introduction Depression-related mood disorders affect millions of people worldwide and contribute to substantial morbidity and disability, yet little is known about the effects of work scheduling on depression. This study used a large Swedish survey to prospectively examine the effects of work schedule on registry-based antidepressant prescriptions in females and males over a 2-year period. Methods The study was based on an approximately representative sample ( $\mathrm{n}=3980$ males, 4663 females) of gainfully employed participants in the Swedish Longitudinal Occupational Survey of Health. Sex-stratified analyses were conducted using logistic regression. For exposure, eight categories described work schedule in 2008: 'regular days' (three categories of night work history: none, $\leq 3$ years, 4+ years), 'night shift work', 'regular shift work (no nights)', 'rostered work (no nights)', 'flexible/non-regulated hours' and 'other'. For the primary outcome measure, all prescriptions coded N06A according to the Anatomical Therapeutic Chemical System were obtained from the Swedish National Prescribed Drug Register and dichotomised into 'any' or 'no' prescriptions between 2008 and 2010. Estimates were adjusted for potential sociodemographic, health and work confounders, and for prior depressive symptoms.

Results In 2008, $22 \%$ of females versus $19 \%$ of males worked outside of regular daytime schedule. Registered antidepressant prescription rates in the postsurvey period were $11.4 \%$ for females versus $5.8 \%$ for males. In fully adjusted models, females in 'flexible/non-regulated' schedules showed an increased OR for prospective antidepressant prescriptions $(\mathrm{OR}=2.01,95 \% \mathrm{Cl}=1.08$ to 3.76). In males, odds ratios were most increased in those working 'other' schedules $(\mathrm{OR}=1.72,95 \% \mathrm{Cl}=0.75$ to 3.94) and 'Regular days with four or more years' history of night work' ( $\mathrm{OR}=1.54,95 \% \mathrm{Cl}=0.93$ to 2.56 ).

Conclusions This study's findings support a relationship between work schedule and prospective antidepressant prescriptions in the Swedish workforce. Future research should continue to assess sex-stratified relationships, using detailed shift work exposure categories and objective registry data where possible.

\section{INTRODUCTION}

An individual's work schedule characteristics may bear an important influence on

\section{Strengths and limitations of this study}

Two-year longitudinal design

- Based on a large national survey (the Swedish Longitudinal Occupational Survey of Health) with detailed information on workplace, demographic and social characteristics.

- Addresses a number of common methodological limitations in shift work research through its use of detailed exposure assessment, objectively recorded health outcome measures and sex-stratified analyses.

- Other characteristics that have been linked with negative mental health outcomes, such as long weekly working hours, short shift durations and the presence/characteristics of shift rotations should also be considered in future studies.

their mental health. On the one hand, high levels of work time control have been linked to positive health outcomes such as affective well-being and perceived stress. On the other hand, shift work has been linked to increased symptoms of depression and negative mood compared with regular day work. ${ }^{1-4}$ Shift workers may be at increased risk of developing mental disorders such as depression due to biological and social disturbances that are caused by their work schedules. ${ }^{56}$ Sleep disturbances in shift workers are well documented $^{7-9}$; these represent the most widely reported circadian disruptions associated with depression. ${ }^{10}$ Exposure to light-at-night has also been linked to mental health effects, both directly and through its suppression of melatonin. ${ }^{11-13}$ Finally, the social zeitgeber theory postulates that stressful life events may trigger depressive episodes by disrupting social routines. ${ }^{6}$

Depressive disorders are prevalent in western countries, ${ }^{14}$ and contribute to substantial morbidity and disability worldwide. ${ }^{1516}$ However, studies of the association between work schedule and clinically 
verified mental illness such as depression remain relatively scarce. Furthermore, methodological challenges are an important limitation when examining associations between work schedule and mental health. ${ }^{17}$ First, a lack of clear and well defined exposure definitions increase the potential for measurement error and misclassification bias $^{18}$ that can attenuate effect estimates, as shown in prior analyses of shift work and depression. ${ }^{19}$ Second, mental health outcomes are often measured through subjective reporting, that is more susceptible to bias compared with objective health outcome data, particularly given the social stigma attached to poor mental health. ${ }^{20}$ Third, sex-stratified analyses are biologically valid and important to conduct yet this is not always done; an important consideration since both work schedule ${ }^{21}$ and rates of reported depressive disorders ${ }^{16}$ are known to differ across males and females. There is some evidence of differential impacts of shift work on mental health by $\operatorname{sex}^{22}{ }^{23}$ although the evidence is inconsistent across studies. Finally, self-selection of individuals in to and out of jobs with non-standard work hours (the 'healthy worker effect') can bias results towards underestimated effects and is particularly problematic when past exposures are not accounted for.

To address these challenges, the present study used data from the Swedish Longitudinal Occupational Survey of Health (SLOSH).$^{24}$ This large national survey collected detailed information on workplace, demographic and social characteristics, and can be linked to national health registries in Sweden. We examined the prospective effect of work schedule (using detailed categories that considered prior night work history) on antidepressant prescription rates (using objective measures obtained via linkage to a national health registry), in females and in males, over a 2-year period.

Shift work, especially where it involves night work, could be expected to increase rates of antidepressant prescriptions, due to the chronic disruption of circadian rhythms, sleep and social routines. Female shift workers are expected to show higher prescription rates than their male counterparts, due to the double burden of shift working and family responsibilities, ${ }^{25}$ higher emotional job demands ${ }^{26}$ and possible psychobiological gender differences in the impact of circadian disruption. ${ }^{27}$ The impact of flexible work hours on antidepressant prescription rates is more difficult to predict. While having control over one's work hours is potentially beneficial, it may also lead to overwork. Thus, no predictions were made with respect to associations between flexible work and antidepressant prescription rates.

\section{METHODS}

\section{Patient and public involvement}

This study is based on an approximately representative sample of gainfully employed Swedish individuals participating in SLOSH. SLOSH is a follow-up of Swedish Work Environment Survey participants, a biennial sample of gainfully employed individuals drawn from the Swedish Labor Force Survey. The general aim of SLOSH is to investigate longitudinal relationships between work environment (particular ly psychosocial aspects), labour market participation, and health and well-being, among others.

Participants were not directly involved in any part of the current study; information about research results is provided to all participants by means of a public web page (www.slosh.se).

\section{Study sample}

The baseline study sample was drawn from the $n=9756$ participants who were currently working in the 2008 SLOSH survey wave (this wave was chosen since it yielded a relatively large number of respondents, and collected information on history of night work). This sample was limited to respondents who provided valid answers for work schedule (excluded $n=195$ ), who did not work a regular evening schedule due to small numbers in this category (excluded $n=58$ ), who worked between 8 and 70 hours per week (excluded $n=25$ reporting fewer than 8 hours per week, $\mathrm{n}=12$ reporting more than 70 hours per week and $\mathrm{n}=355$ with missing data) and who provided valid answers for all other variables included in the models. This produced an analytic sample of $n=8643$ respondents in the 2008 SLOSH wave.

\section{Primary exposure and outcome}

Eight categories were used to describe work schedule in 2008: 'regular days with no history of night work', 'regular days with history of night work $\leq 3$ years', 'regular days with history of night work $\geq 4$ years', 'night work (regular, rostered or rotating)', 'regular shift work (no nights)', 'rostered work (no nights)', 'flexible/non-regulated hours' and 'other'. Regular shift work involves working a set of invariantly timed shifts that cycle according to fixed sequence. Rostered work also involves invariantly timed shifts, but the sequence is more ad hoc such that the employee has relatively short notice of which shifts they will be working. Flexible/non-regulated hours involve duty-periods that could vary both with respect to the start and finish times, and which days are worked.

Data on antidepressant medication prescriptions were obtained from the Swedish National Prescribed Drug Register. This register contains information on all prescribed drugs dispensed from Swedish pharmacies since July 2005 (except for those given in hospitals or nursing homes). These data were anonymously linked to survey respondents through registered personal identification numbers. All Drug Register prescriptions coded N06A according to the Anatomical Therapeutic Chemical System $^{28}$ were extracted for the analyses. A dichotomous variable ('yes' or 'no' was created to describe any antidepressant prescriptions registered between 17 June 2008 and 31 December 2010, representing a period of approximately 2.5 years following the 2008 survey wave; 17 June 2008 represents the date on which $75 \%$ of responses were received from the 2008 SLOSH wave participants. 


\section{Analyses}

Logistic regression models were used to examine the prospective association between work schedule reported in 2008 and subsequent antidepressant prescriptions for males and females separately. Model estimates were adjusted for the potentially confounding effects of other variables hypothesised as being risk factors for depression and also related to work schedule (see table 1 for detail).

Demographic and social variables included age, self-described chronotype, significant other status, education and the presence of chronic conditions; work variables included employer type, weekly number of hours worked, emotional demands at work, demand-control at work and social support at work.

Previous depression and/or previous antidepressant prescriptions was described with two categories: 'yes' and 'no'. SLOSH respondents were assigned 'yes' if they reported depression in the prior SLOSH wave as assessed with the Symptom Checklist-core depression, ${ }^{29}$ or if they had been prescribed any antidepressant medications (prescriptions coded N06A) in the Swedish National Prescribed Drug Register in the 3 years prior to the 2008 SLOSH wave (1 July 2005-17 June 2008).

Demographic, work variables and previous depression and/or previous antidepressant prescription variables were entered sequentially as covariates to examine how these factors impacted effect estimates.

\section{RESULTS}

Table 1 summarises variables within the study sample $(\mathrm{n}=8643)$. Females represented $54 \%$ of the total sample. The majority of all respondents $(\mathrm{n}=6874$, or $80 \%)$ reported regular daytime work in 2008; of these, $n=1088$ $(16 \%)$ had previously worked nights. For females, $\mathrm{n}=3639$ $(78 \%)$ reported regular daytime work in 2008; of these, $\mathrm{n}=449(12 \%)$ had previously worked nights. For males, $\mathrm{n}=3235(81 \%)$ reported regular daytime work in 2008; of these, $n=639(20 \%)$ had previously worked nights. Registered antidepressant prescription rates in the postsurvey period were $11.4 \%$ for females versus $5.8 \%$ for males. The highest rates of registered antidepressant prescriptions occurred in both females and males reporting 'other' work hours. For females, this was followed by 'flexible/non-regulated' hours and 'roster work, days and evenings only'. For males, this was followed by 'regular days (4+ years of night work history)' and 'regular days (3 years or less of night work history)'.

In unadjusted analyses (table 2), an increased OR for depression was observed for 'other' work hours in both male $(\mathrm{OR}=1.87,95 \% \mathrm{CI}=0.95$ to 3.67$)$ and female $(\mathrm{OR}=1.62,95 \% \mathrm{CI}=1.05$ to 2.51$)$ models; in adjusted models these effects persisted but CIs widened to non-significance at the $\mathrm{p}=0.05$ level for both sexes. In models adjusted for demographic and work variables as well as previous depressive symptoms, females in 'flexible/ non-regulated' schedules showed an increased OR for depression ( $\mathrm{OR}=2.01,95 \% \mathrm{CI}=1.08$ to 3.76$)$, while the strongest increases in males were observed for those working 'other' schedules $(\mathrm{OR}=1.72,95 \% \mathrm{CI}=0.75$ to $3.94)$ and 'regular days with 4 or more years' history of night work' $(\mathrm{OR}=1.54,95 \% \mathrm{CI}=0.93$ to 2.56$)$.

\section{DISCUSSION}

The SLOSH survey's extensive information on working time was used to develop an exposure variable with eight work schedule categories, a unique level of detail that reduced the potential for misclassification bias. This study's use of objective measures of antidepressant drug prescriptions from a comprehensive nation-wide registry minimized the potential for subjective bias in reporting, the latter being particularly important for a widely stigmatised outcome such as mental health. ${ }^{20}$

Shift work involving nights and early mornings is generally thought to confer the greatest risk of circadian disruption $^{30} 31$ and may negatively impact on mental health in a number of ways. ${ }^{5}$ Our results suggest that other work scheduling factors also play an important role in the development of depressive symptoms requiring pharmaceutical treatment.

In the final models adjusted for demographics, work and prior symptoms of depression, the strongest effect for prospective antidepressant prescription=yes was observed in females reporting flexible or non-regulated work hours. There are two (non-exclusive) forms of flexible working time arrangements: organisation-orientated flexibility, where the hours of work are determined by the employer (eg, on-call work); and employee-orientated flexibility which is associated with high levels of worktime control. ${ }^{32}$ Several strands of evidence suggest that employee-orientated flexibility was relatively high among those in the current sample working flexible or non-regulated hours. For example, work time control was higher in this category of work schedule than any other category. ${ }^{33}$ The proportion of respondents with managerial roles (generally associated with greater work time control) was substantially higher in this category of work schedule (57.8\% of males and $43.9 \%$ of females) than in the entire SLOSH sample (43.9\% and $27.2 \%$, respectively) (results not shown). Typical occupational categories within the flexible/non-regulated work hours category include several that are commonly associated with high levels of work time control and boundaryless working (ie, where employees can decide for themselves when and where to work $\left.^{34}\right)$; namely legislators $(22.4 \%$ of males and $10.0 \%$ of females), professionals $(33.6 \%$ of males and $61.0 \%$ of females) and technical and associate professionals $(27.3 \%$ of males and $12.8 \%$ of females). It therefore seems likely the respondents in this schedule category were often in positions of high responsibility and were more likely to be engaged in boundaryless work.

High levels of work time control have been shown to positively influence mental health outcomes such as affective well-being and perceived stress. ${ }^{35}$ The potentially beneficial effects of allowing employees control 
Table 1 Baseline characteristics of study sample and univariate relationships with prospective antidepressant prescriptions between 2008 and 2010

\begin{tabular}{|c|c|c|c|c|c|c|}
\hline & \multicolumn{6}{|c|}{$\begin{array}{l}\text { One or more antidepressant prescriptions registered between } 17 \text { June } 2008 \\
\text { and } 31 \text { December } 2010\end{array}$} \\
\hline & \multicolumn{3}{|c|}{ Female } & \multicolumn{3}{|c|}{ Male } \\
\hline & Total (\%) & No (\%) & Yes (\%) & Total (\%) & No (\%) & Yes (\%) \\
\hline Total & $4663(100)$ & $4132(88.6)$ & $531(11.4)$ & $3980(100)$ & 3751 (94.2) & $229(5.8)$ \\
\hline \multicolumn{7}{|l|}{ Work schedule, 2008} \\
\hline Regular days (0years hx night work) & 3190 & $2842(89.1)$ & $348(10.9)$ & 2596 & $2452(94.5)$ & $144(5.5)$ \\
\hline Regular days ( $\leq 3$ years night work $\mathrm{hx}$ ) & 253 & $222(87.7)$ & $31(12.3)$ & 315 & 294 (93.3) & $21(6.7)$ \\
\hline Regular days (4+ years night work $\mathrm{hx}$ ) & 196 & $174(88.8)$ & $22(11.2)$ & 324 & $298(92.0)$ & $26(8.0)$ \\
\hline Nights (regular, roster or rotating) & 282 & $251(89.0)$ & $31(11.0)$ & 298 & $283(95.0)$ & $15(5.0)$ \\
\hline $\begin{array}{l}\text { Regular shift work, days and evenings } \\
\text { only }\end{array}$ & 229 & $204(89.1)$ & $25(10.9)$ & 148 & $144(97.3)$ & $4(2.7)$ \\
\hline Roster work, days and evenings only & 233 & $202(86.7)$ & $31(13.3)$ & 63 & $60(95.2)$ & $3(4.8)$ \\
\hline Flexible/non-regulated hours & 123 & $106(86.2)$ & $17(13.8)$ & 135 & $129(95.6)$ & $6(4.4)$ \\
\hline Other work hours & 157 & $131(83.4)$ & $26(16.6)$ & 101 & $91(90.1)$ & $10(9.9)$ \\
\hline \multicolumn{7}{|l|}{ Age group } \\
\hline 20-35years & 640 & $582(90.9)$ & $58(9.1)$ & 604 & 579 (95.9) & $25(4.1)$ \\
\hline $36-50$ years & 1897 & $1672(88.1)$ & $225(11.9)$ & 1527 & $1433(93.8)$ & $94(6.2)$ \\
\hline $51-70$ years & 2126 & $1878(88.3)$ & $248(11.7)$ & 1849 & $1739(94.1)$ & $110(5.9)$ \\
\hline \multicolumn{7}{|l|}{ Chronotype } \\
\hline Distinctly or somewhat a morning person & 1859 & $1675(90.1)$ & $184(9.9)$ & 1458 & $1383(94.9)$ & $75(5.1)$ \\
\hline Neither & 1244 & $1076(86.5)$ & $168(13.5)$ & 1030 & $975(94.7)$ & $55(5.3)$ \\
\hline Distinctly or somewhat an evening person & 1560 & $1381(88.5)$ & $179(11.5)$ & 1492 & $1393(93.4)$ & $99(6.6)$ \\
\hline \multicolumn{7}{|l|}{ Significant other status } \\
\hline Single & 1023 & $875(85.5)$ & $148(14.5)$ & 794 & $743(93.6)$ & $51(6.4)$ \\
\hline Married/cohabitating & 3640 & 3257 (89.5) & $383(10.5)$ & 3186 & 3008 (94.4) & $178(5.6)$ \\
\hline \multicolumn{7}{|l|}{ Education } \\
\hline Compulsory & 622 & $530(85.2)$ & $92(14.8)$ & 607 & $564(92.9)$ & $43(7.1)$ \\
\hline Upper secondary/vocational training & 1933 & $1725(89.2)$ & $208(10.8)$ & 2143 & $2039(95.1)$ & $104(4.9)$ \\
\hline University or equivalent & 2108 & $1877(89.0)$ & $231(11.0)$ & 1230 & 1148 (93.3) & $82(6.7)$ \\
\hline \multicolumn{7}{|l|}{ Chronic conditions $^{*}$} \\
\hline None & 3132 & $2833(90.5)$ & $299(9.5)$ & 2609 & $2497(95.7)$ & $112(4.3)$ \\
\hline One or more & 1531 & $1299(84.8)$ & $232(15.2)$ & 1371 & $1254(91.5)$ & $117(8.5)$ \\
\hline \multicolumn{7}{|l|}{ Employer type } \\
\hline Private company & 1499 & $1345(89.7)$ & $154(10.3)$ & 2565 & $2430(94.7)$ & $135(5.3)$ \\
\hline $\begin{array}{l}\text { Other (association/non-profit, own } \\
\text { business/farm or other) }\end{array}$ & 367 & $327(89.1)$ & $40(10.9)$ & 413 & $388(93.9)$ & $25(6.1)$ \\
\hline Government (local, district or central) & 2797 & $2460(88.0)$ & $337(12.0)$ & 1002 & $933(93.1)$ & $69(6.9)$ \\
\hline \multicolumn{7}{|l|}{ Work hours } \\
\hline 8-31 hours/week & 993 & $829(83.5)$ & $164(16.5)$ & 251 & $218(86.9)$ & $33(13.1)$ \\
\hline$\geq 32$ hours/week & 3670 & $3303(90.0)$ & 367 (10.0) & 3729 & $3533(94.7)$ & $196(5.3)$ \\
\hline \multicolumn{7}{|l|}{ Demand-control at work $\dagger$} \\
\hline Low demands, low control & 1122 & $1014(90.4)$ & $108(9.6)$ & 946 & $905(95.7)$ & $41(4.3)$ \\
\hline High demands, low control & 897 & 762 (84.9) & $135(15.1)$ & 671 & $629(93.7)$ & $42(6.3)$ \\
\hline Low demands, high control & 1299 & $1153(88.8)$ & $146(11.2)$ & 1234 & $1157(93.8)$ & $77(6.2)$ \\
\hline High demands, high control & 1345 & $1203(89.4)$ & $142(10.6)$ & 1129 & 1060 (93.9) & $69(6.1)$ \\
\hline
\end{tabular}


One or more antidepressant prescriptions registered between 17 June 2008 and 31 December 2010

\begin{tabular}{|c|c|c|c|c|c|c|}
\hline & \multicolumn{3}{|l|}{ Female } & \multicolumn{3}{|l|}{ Male } \\
\hline & Total (\%) & No (\%) & Yes (\%) & Total (\%) & No (\%) & Yes (\%) \\
\hline \multicolumn{7}{|l|}{ Social support at work † } \\
\hline High & 2296 & 2056 (89.5) & $240(10.5)$ & 1816 & $1720(94.7)$ & $96(5.3)$ \\
\hline \multicolumn{7}{|c|}{ Emotional demands at work $\ddagger$} \\
\hline Seldom or never & 1775 & $1606(90.5)$ & $169(9.5)$ & 2441 & $2310(94.6)$ & $131(5.4)$ \\
\hline \multicolumn{7}{|c|}{ Depression in 2006 or antidepressant prescription, 2005-2008 } \\
\hline No & 3895 & $3740(96.0)$ & $155(4.0)$ & 3647 & $3552(97.4)$ & $95(2.6)$ \\
\hline Yes & 768 & $392(51.0)$ & $376(49.0)$ & 333 & $199(59.8)$ & $134(40.2)$ \\
\hline
\end{tabular}

`Based on the questions 'Has a doctor told you that you have': 'heart disease', 'diabetes', 'rheumatic disorder', 'musculoskeletal disorder', 'obstructive pulmonary disease' or 'asthma'.

†Based on the 17-question Swedish Demand-Control-Support Questionnaire scale. ${ }^{54}$

$\ddagger$ Based on the question 'Does your work put you in emotionally disturbing situations?'

$\mathrm{hx}$, history.

over their work hours has been ascribed to the promotion of a positive balance between effort and recovery, and between work and non-work life. ${ }^{35}$ However, the flexibility of boundaryless work may also have negative consequences. ${ }^{36}$ When workloads are high and there are ambiguous norms about work hours, employees may feel pressured to restructure their personal time to work, resulting in overwork. ${ }^{37}$ Mixing work and family time may also produce difficulties 'switching off' thoughts of work, such that work never stops, thereby increasing stress and impeding recovery. ${ }^{32}$

While the potential negative effects of boundaryless work have been discussed elsewhere ${ }^{32} 37$ the current study is the first to identify an association with objective measures of mental health. That the effect was greater among females is consistent with a scenario in which females with flexible work hours are more likely than males to use the flexibility to engage in additional non-work responsibilities, rather than using the increased control to fully recover and reduce strain outcomes. ${ }^{38} \mathrm{In}$ addition to leading to impaired recovery, such a scenario may increase work-life conflict that can negatively affect marital relationships and parental roles, and may also lead to increased sleep problems, chronic fatigue and psychosomatic symptoms, ${ }^{39}$ with potentially negative consequences for mental health. ${ }^{40}$

\section{Strengths and limitations}

SLOSH is based on a nationally representative sample of the Swedish working population, therefore results are generalisable to a wide range of occupations. Antidepressant prescription rates in this study are comparable with other Nordic countries, further strengthening the generalisability of our results. For example, antidepressant prescription rates of $5.3 \%$ have been noted among public sector employees in Finland ${ }^{41}$ and $6.5 \%$ in Denmark. ${ }^{42}$

SLOSH collected a breadth of detail on work and work-schedule characteristics, such as weekly work hours, history of night work and demand-control, social support and emotional demands at work. However, other characteristics that have been linked with negative mental health outcomes, such as long weekly working hours, ${ }^{43}$ relatively short shift durations ${ }^{44}$ and the presence/characteristics of shift rotations ${ }^{4546}$ were not included, and should be considered in future studies.

This prospective study assessed antidepressant prescriptions in an approximately 2-year period following the assessment of work schedule in 2008, providing a stronger base for assessing causality as compared with a cross-sectional study design. Although a longer time lag would be necessary to reduce the possibility of reverse causality for chronic outcomes (such as cancer), depression is a relatively quick-onset disease, so a 2-year follow-up was deemed to be sufficient.

To further reduce the potential for reverse causality, the final models were adjusted for prior depression (as reported in the $2006 \mathrm{SLOSH}$ ) and prior antidepressant prescriptions in the 3 years prior to the 2008 SLOSH. While restriction to individuals without a prior history of depression or antidepressant prescriptions would have been most appropriate for an inception cohort, this is not the case with SLOSH, where individuals worked various types of schedules prior to their participation in the survey. If a 'clean' cohort had been assumed (ie, if prior exposures and outcomes at a participant's time of entry into SLOSH were ignored), and work schedule affected antidepressant prescription rates, the effect of work schedule on antidepressant prescription rates 


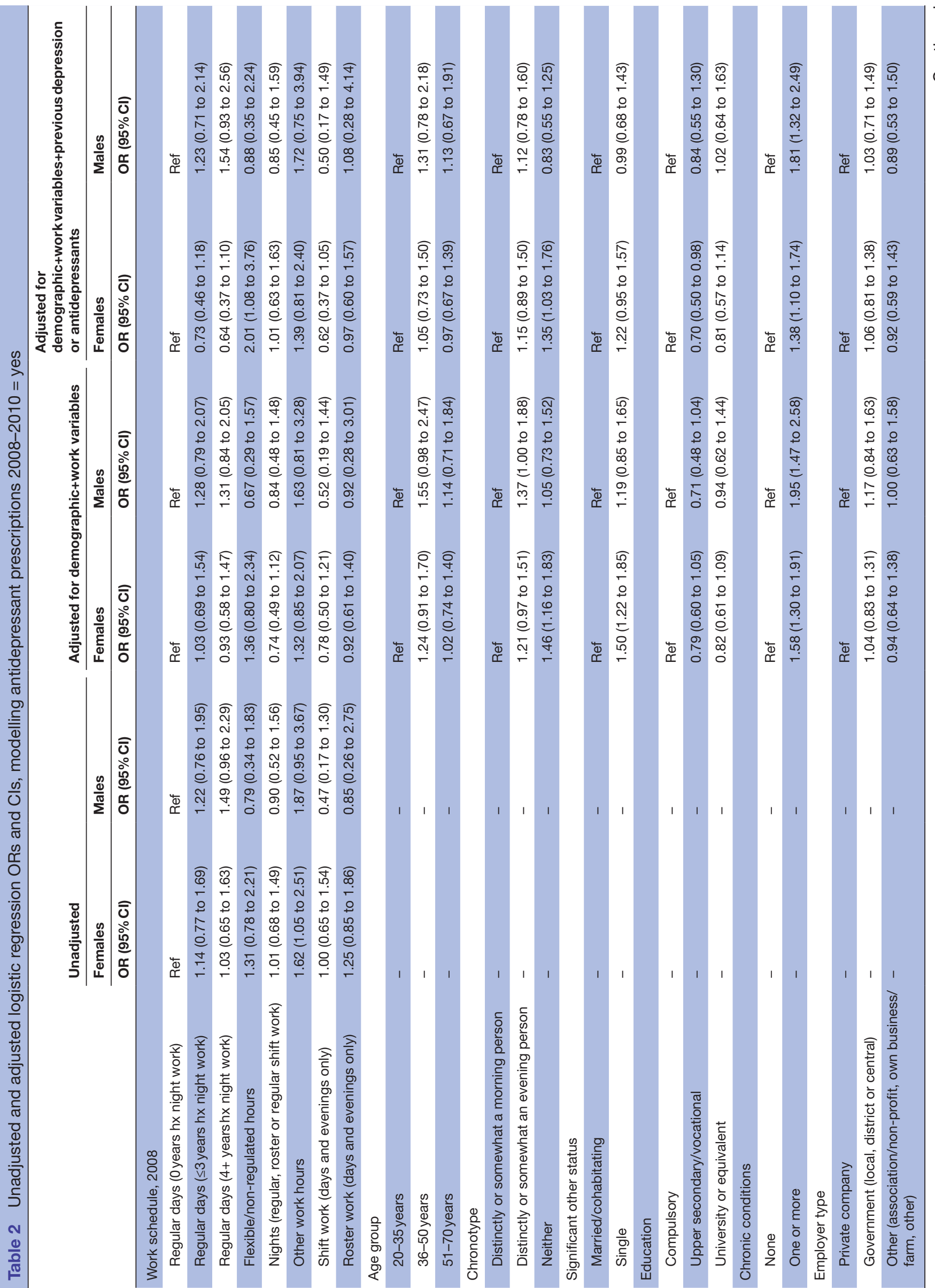

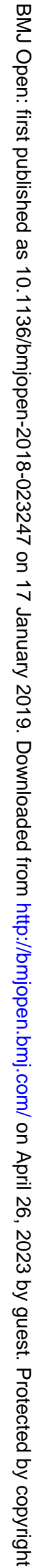




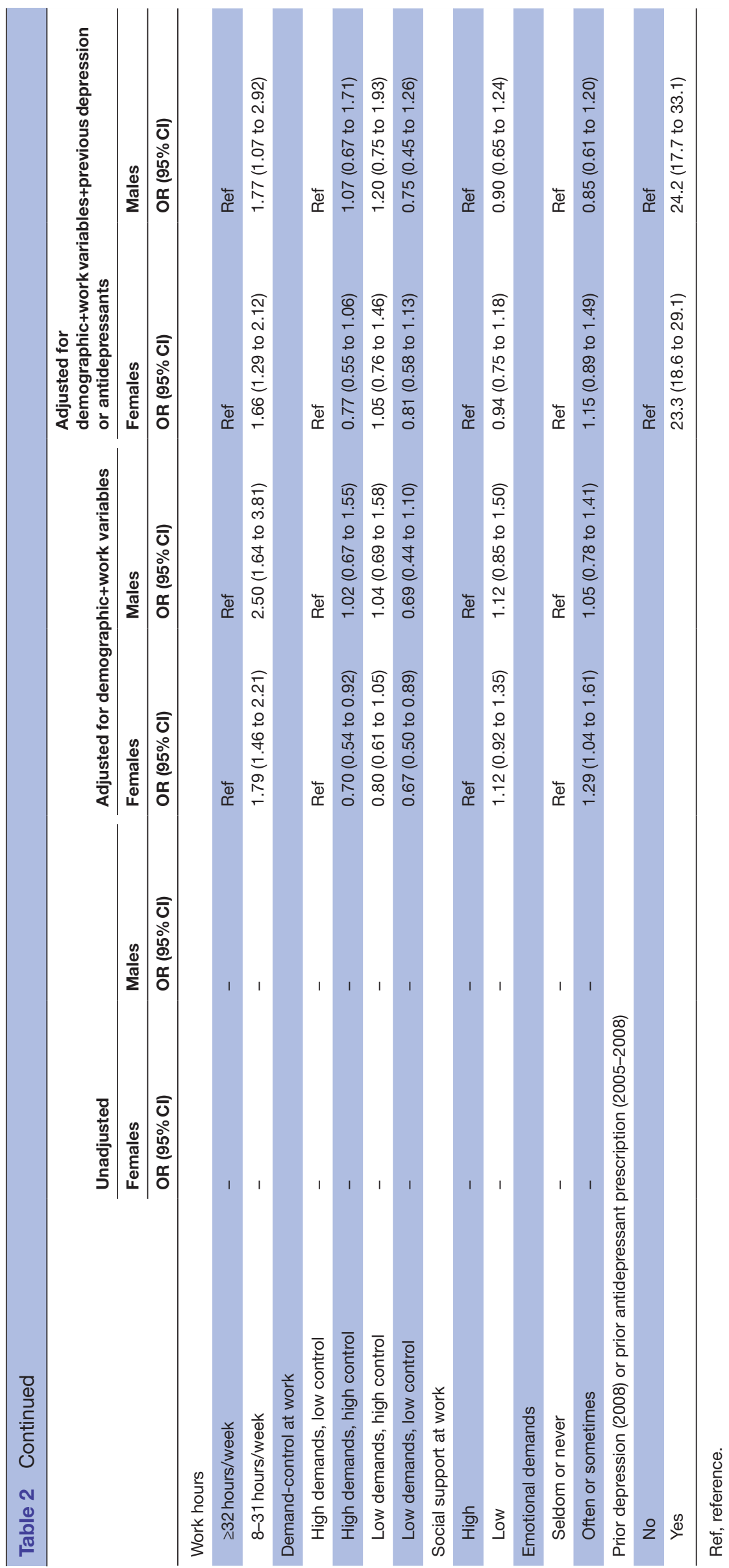

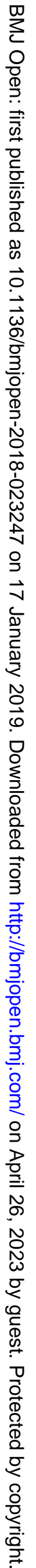


would be underestimated to an unknown extent. The exclusion of over 1000 individuals with prior depression/ antidepressant prescriptions would also have precluded the use of detailed exposure categories, a major goal of the analyses. For these reasons, adjustment was applied rather than restriction. This may have resulted in residual confounding, given the strength of the association with prior depression or prior antidepressant prescription (see table 2).

Self-selection in to and out of certain types of work schedule, where differential movement of workers out of 'harmful' schedules produces a workforce of shift workers that is healthier than day workers, is a common methodological challenge in shift work research. ${ }^{17}$ For example, recent longitudinal studies have shown that the presence of depressive symptoms ${ }^{3}$ and other depression-related outcomes $^{47}$ at baseline is associated with a change in work schedule (leaving night work). This phenomenon tends to bias results towards underestimated effects, due to a diluted reference group that contains both day and former shift workers. While this 'healthy worker' bias presents a challenge to any observational study, its impacts on observed effects can be better understood and accounted for using longitudinal study designs and information on past work history. In the current study, self-selection out of shift work was accounted for by creating a reference category of day workers with no prior history of working night shifts. This is a strength compared with many other studies where self-selection bias is simply ignored, however it still does not account for primary self-selection in to shift work (eg, at the start of an individual's working life). This 'clean' reference group also implicitly assumes that night work is the most disruptive form of shift work with respect to mental health outcomes which, as the current findings suggest, may not be the case. Despite these potential sources of misclassification, relationships between work schedule and antidepressant prescriptions were nonetheless observed in this study.

An additional strength of this study is the use of objective registry-based outcome measures, that are relatively rare in this area of the literature and may be used to support causal inference in an emerging area of shift work and health research. ${ }^{42}$ The Prescribed Drug Register provides good coverage of the Swedish population ${ }^{48}$ and avoids issues of self-report bias. Our use of objective antidepressant prescriptions measures (that were recorded independently of survey participation) also precluded attrition-related bias, since outcomes were available regardless of participation in the subsequent survey wave. However, the cutpoint used to assess prospective antidepressant use (the date on which $75 \%$ of responses were received from participants in the 2008 SLOSH wave) may have introduced a small degree of misclassification, for example, if any of the $25 \%$ remaining individuals were prescribed antidepressants after the cutpoint but prior to submitting their survey responses.

Despite the benefits of this objective outcome measure, the use of antidepressant drug prescription rates as a proxy for mood disorders is associated with a number of limitations. First, it should be acknowledged that various factors (eg, treatment seeking behaviours, clinician recognition and treatment of depressive disorders) influence drug prescription statistics. ${ }^{49-51}$ Furthermore, not all individuals with depression or other mood disorders are treated with antidepressant medications. ${ }^{4950}$ Finally, while antidepressant medications are primarily prescribed for the treatment of depression, they can also be used in the treatment of other mental disorders and somatic diseases such as sleeping problems, anxiety or pain. ${ }^{4952}$ This being said, the validity of using antidepressant medication prescriptions as an outcome measure (12-month prevalence of 6.0\% in 2008) is strengthened by its comparability with a prior Swedish sample from Stockholm county, where 12-month prevalence of depressive disorders was reported among $4.1 \%$ of males and $6.6 \%$ of females. ${ }^{53}$

Specifying work schedule with eight exposure categories, along with the stratification by gender, meant that some cell sizes in the analyses were low. Thus, it is possible that some of the non-significant associations were a result of inadequate statistical power.

\section{CONCLUSIONS}

This 2-year prospective study addresses a number of known methodological issues in work schedule epidemiology through its use of a longitudinal design, detailed exposure assessment, health outcomes obtained from a national registry and sex-stratified analyses. Findings indicate the presence of a relationship between work schedule and subsequent antidepressant medication prescriptions. A clearer understanding of work schedule's effects on mental health may be facilitated by additional research using inception cohorts and enhanced detail on work factors with potential impacts on mental health.

Acknowledgements The authors thank Viktor Persson for his assistance with SLOSH data extraction and linkage.

Contributors CL participated in Swedish Longitudinal Occupational Survey of Health (SLOSH) data collection. ALH, GK and PT conceptualised the current study design; ALH performed statistical analyses and drafted the manuscript. All authors participated in interpreting the data and revising the manuscript.

Funding The project was supported by the Swedish Research Council for Health, Working Life and Welfare (grant number 2016-07150) which provided support for PT, CL and GK, and for the costs of publication. At the time of analyses and writing, ALH was supported by WorkSafeBC's Research Training Award Program and a postdoctoral fellowship from the International Agency for Research on Cancer. GK and CL were also supported by funding from "NordForsk, Nordic Program on Health and Welfare (74809)". SLOSH has been supported by the Swedish Research Council for Health, Working Life and Welfare (FORTE) [grant \#2005-0734 and \#2009-1077], the Swedish Research Council (VR) [\#2009-6192, \#825-2013-1645 and \#8212013-1646] and through the Stockholm Stress Centre of Excellence financed by the Swedish Research Council for Health, Working Life and Welfare [\#2009-1758].

Competing interests None declared.

Patient consent for publication Not required.

Ethics approval SLOSH was approved by the Stockholm Regional Research Ethics Board.

Provenance and peer review Not commissioned; externally peer reviewed.

Data sharing statement Due to legal restrictions, the SLOSH data cannot be made publicly available. We are not permitted to share the dataset underlying our findings 
since this would compromise the integrity and privacy of study participants. For data requests please contact the SLOSH data manager, Constanze Leineweber, at constanze.leineweber@su.se

Open access This is an open access article distributed in accordance with the Creative Commons Attribution Non Commercial (CC BY-NC 4.0) license, which permits others to distribute, remix, adapt, build upon this work non-commercially, and license their derivative works on different terms, provided the original work is properly cited, appropriate credit is given, any changes made indicated, and the use is non-commercial. See: http://creativecommons.org/licenses/by-nc/4.0/.

\section{REFERENCES}

1. Moon HJ, Lee SH, Lee HS, et al. The association between shift work and depression in hotel workers. Ann Occup Environ Med 2015;27:29-39.

2. Bara AC, Arber S. Working shifts and mental health--findings from the British Household Panel Survey (1995-2005). Scand J Work Environ Health 2009;35:361-7.

3. Driesen K, Jansen NW, van Amelsvoort LG, et al. The mutual relationship between shift work and depressive complaints-a prospective cohort study. Scand J Work Environ Health 2011;37:402-10.

4. Geiger-brown J, Muntaner C, Lipscomb J, et al. Demanding work schedules and mental health in nursing assistants working in nursing homes. Work Stress 2004;18:292-304.

5. McClung CA. How might circadian rhythms control mood? Let me count the ways.... Biol Psychiatry 2013;74:242-9.

6. Grandin LD, Alloy LB, Abramson LY. The social zeitgeber theory, circadian rhythms, and mood disorders: review and evaluation. Clin Psychol Rev 2006;26:679-94.

7. Sallinen M, Kecklund G. Shift work, sleep, and sleepiness differences between shift schedules and systems. Scand J Work Environ Health 2010;36:121-33.

8. Pilcher JJ, Lambert BJ, Huffcutt Al. Differential effects of permanent and rotating shifts on self-report sleep length: a meta-analytic review. Sleep 2000;23:1-9.

9. Akerstedt T, Wright KP. Sleep loss and fatigue in shift work and shift work disorder. Sleep Med Clin 2009;4:257-71.

10. Monteleone P, Martiadis V, Maj M. Circadian rhythms and treatment implications in depression. Prog Neuropsychopharmacol Biol Psychiatry 2011;35:1569-74.

11. Stephenson KM, Schroder CM, Bertschy G, et al. Complex interaction of circadian and non-circadian effects of light on mood: shedding new light on an old story. Sleep Med Rev 2012;16:445-54.

12. LeGates TA, Altimus $\mathrm{CM}$, Wang $\mathrm{H}$, et al. Aberrant light directly impairs mood and learning through melanopsin-expressing neurons. Nature 2012:491:594-8.

13. Srinivasan V, Smits $M$, Spence W, et al. Melatonin in mood disorders World J Biol Psychiatry 2006;7:138-51.

14. Ferrari AJ, Somerville AJ, Baxter AJ, et al. Global variation in the prevalence and incidence of major depressive disorder: a systematic review of the epidemiological literature. Psychol Med 2013;43:471-81.

15. Paykel ES, Brugha T, Fryers T. Size and burden of depressive disorders in Europe. Eur Neuropsychopharmacol 2005;15:411-23.

16. Ferrari AJ, Charlson FJ, Norman RE, et al. Burden of depressive disorders by country, sex, age, and year: findings from the global burden of disease study 2010. PLoS Med 2013;10:e1001547.

17. Knutsson A. Methodological aspects of shift-work research. Chronobiol Int 2004;21:1037-47.

18. Loomis D, Kromhout $\mathrm{H}$. Exposure variability: concepts and applications in occupational epidemiology. Am J Ind Med 2004;45:113-22.

19. Hall AL, Franche RL, Koehoorn M. Examining exposure assessment in shift work research: a study on depression among nurses. Ann Work Expo Health 2018;62:182-94.

20. The Lancet. The health crisis of mental health stigma. Lancet 2016;387:1027.

21. Williams C. Work-life balance of shift workers. Statistics Canada perspectives. Ottawa, Canada: Statistics Canada, 2008

22. Lee A, Myung SK, Cho JJ, et al. Night shift work and risk of depression: meta-analysis of observational studies. J Korean Med Sci 2017;32:1091-6.

23. Angerer P, Schmook R, Elfantel I, et al. Night work and the risk of depression. Dtsch Arztebl Int 2017;114:404-11.

24. Magnusson Hanson LL, Leineweber C, Persson V, et al. Cohort profile: the Swedish Longitudinal Occupational Survey of Health (SLOSH). Int J Epidemiol 2018;47:691-2.

25. Ogińska H, Pokorski J, Ogiński A. Gender, ageing, and shiftwork intolerance. Ergonomics 1993;36(1-3):161-8.
26. Sverke M, Falkenberg $\mathrm{H}$, Kecklund $\mathrm{G}$, et al. Women and men and their working conditions: the importance of organizational and psychosocial factors for work-related and health-related outcomes. Stockholm, Sweden, 2017.

27. Santhi N, Lazar AS, McCabe PJ, et al. Sex differences in the circadian regulation of sleep and waking cognition in humans. Proc Natl Acad Sci U S A 2016;113:E2730-E2739.

28. WHO ATC. Anatomical Therapeutic Chemical classification system. Oslo, Norway: WHO Collaborating Center for Drug Statistics, 2017.

29. Magnusson Hanson LL, Westerlund H, Leineweber C, et al. The Symptom Checklist-core depression (SCL-CD6) scale: psychometric properties of a brief six item scale for the assessment of depression. Scand J Public Health 2014;42:82-8.

30. International Agency for Research on Cancer. IARC monographs on the evaluation of carcinogenic risks to humans volume 98: painting, firefighting and shiftwork. Lyon, France, 2010.

31. Haus E, Smolensky M. Biological clocks and shift work: circadian dysregulation and potential long-term effects. Cancer Causes Control 2006;17:489-500.

32. Kecklund G, Beckers DGJ, Leineweber C, et al. How does work fit with my life? the relation between flexible work arrangements, work-life balance and recovery from work. In: Chmiel N, Fraccarolo F, Sverke M, eds. An introduction to work and organizational psychology. Oxford, UK: John Wiley \& Sons, Ltd, 2017:430-47.

33. Albrecht SC, Kecklund G, Tucker P, et al. Investigating the factorial structure and availability of work time control in a representative sample of the Swedish working population. Scand J Public Health 2016:44:320-8.

34. Beckers DG, Kompier MA, Kecklund G, et al. Worktime control: theoretical conceptualization, current empirical knowledge, and research agenda. Scand J Work Environ Health 2012;38:291-7.

35. Nijp HH, Beckers DG, Geurts SA, et al. Systematic review on the association between employee worktime control and work-non-work balance, health and well-being, and job-related outcomes. Scand J Work Environ Health 2012;38:299-313.

36. Mellner C, Kecklund G, Kompier M, et al. Boundaryless work, psychological detachment and sleep: does working 'anytime anywhere' equal employees are 'always on'? De Leede J, ed. New ways of working practices (advanced series in management): Emerald Group Publishing Ltd, 2016:29-47.

37. Kossek EE, Lee MD. Implementing a reduced-workload arrangement to retain high talent: A case study. The Psychologist-Manager Journal 2008;11:49-64.

38. Hammer LB, Neal MB, Newsom JT, et al. A longitudinal study of the effects of dual-earner couples' utilization of family-friendly workplace supports on work and family outcomes. J Appl Psychol 2005;90:799-810.

39. Costa G. Shift work and health: current problems and preventive actions. Saf Health Work 2010;1:112-23.

40. Allen TD, Herst DE, Bruck CS, et al. Consequences associated with work-to-family conflict: a review and agenda for future research. $J$ Occup Health Psychol 2000;5:278-308.

41. Virtanen M, Kivimäki M, Ferrie JE, et al. Temporary employment and antidepressant medication: a register linkage study. J Psychiatr Res 2008;42:221-9.

42. Bonde JP, Munch-Hansen T, Wieclaw J, et al. Psychosocial work environment and antidepressant medication: a prospective cohort study. BMC Public Health 2009;9:262.

43. Virtanen M, Ferrie JE, Singh-Manoux A, et al. Long working hours and symptoms of anxiety and depression: a 5-year follow-up of the Whitehall II study. Psychol Med 2011;41:2485-94.

44. Lowden A, Kecklund G, Axelsson J, et al. Change from an 8-hour shift to a 12-hour shift, attitudes, sleep, sleepiness and performance. Scand J Work Environ Health 1998;24 Suppl 3(Suppl 3):69-75.

45. Lin PC, Chen CH, Pan SM, et al. Atypical work schedules are associated with poor sleep quality and mental health in Taiwan female nurses. Int Arch Occup Environ Health 2012;85:877-84.

46. Driesen K, Jansen NW, Kant I, et al. Depressed mood in the working population: associations with work schedules and working hours. Chronobiol Int 2010;27:1062-79.

47. Waage S, Pallesen S, Moen BE, et al. Predictors of shift work disorder among nurses: a longitudinal study. Sleep Med 2014;15:1449-55.

48. Furu K, Wettermark B, Andersen M, et al. The Nordic countries as a cohort for pharmacoepidemiological research. Basic Clin Pharmacol Toxicol 2010;106:86-94.

49. Henriksson S, Asplund R, Boëthius G, et al. Infrequent use of antidepressants in depressed individuals (an interview and prescription database study in a defined Swedish population 20012002). Eur Psychiatry 2006;21:355-60. 
50. Demyttenaere K, Bonnewyn A, Bruffaerts R, et al. Clinical factors influencing the prescription of antidepressants and benzodiazepines: results from the European study of the epidemiology of mental disorders (ESEMeD). J Affect Disord 2008;110:84-93.

51. Kivimäki M, Gunnell D, Lawlor DA, et al. Social inequalities in antidepressant treatment and mortality: a longitudinal register study. Psychol Med 2007;37:373.
52. Gardarsdottir H, Heerdink ER, van Dijk L, et al. Indications for antidepressant drug prescribing in general practice in the Netherlands. J Affect Disord 2007;98:109-15.

53. Hällström T, Damström Thakker K, Forsell Y, et al. The PART study: a population based study of mental health in the stockholm county: study design phase I (1998-2000). Stockhom, Sweden: The PART Study Group, 2003.

54. Karasek B, Theorell T. Healthy work: stress, productivity, and the reconstruction of working life. New York, NY: Basic Books, 1990. 